\title{
Introduction to the Special Issue Health Care for All: The Role of Medical Family Therapy
}

\author{
Angela L. Lamson ${ }^{1} \cdot$ Tai J. Mendenhall ${ }^{2}$. Jennifer L. Hodgson ${ }^{1} \cdot$ Chalandra M. Bryant ${ }^{2}$
}

Published online: 10 January 2022

(c) The Author(s), under exclusive licence to Springer Science+Business Media, LLC, part of Springer Nature 2022

While reflecting on the possibilities for a special issue on Medical Family Therapy (MedFT) with the journal of Contemporary Family Therapy, we, the co-editors, began a conversation about some of our personal experiences, our nation's experiences, and our world's experiences with healthcare inequities and the biopsychosocial-spiritual (BPSSEngel, 1977, 1980; Wright et al., 1996) manifestations of acute and prolonged trauma, isolation, and social injustice.

COVID-19, political unrest, economic upheavals, and social injustices created the perfect storm that disproportionately impacted the most vulnerable and most marginalized members of our society. We discussed the physical, emotional, relational, and spiritual exhaustion propelled by this storm, and we collectively grieved. We noted how bearing witness to racial violence and other acts of hate (through recorded and live accounts on social media and television) has shaped, in powerful ways, conversations in our own homes and communities. Some of these conversations have polarized relationships, and some have fostered connections. While systemically oppressed communities work to raise their voices with the aim of creating a society that is both equal and equitable, louder voices and violent actions work to keep those communities silenced. This has resulted in deep, multigenerational wounds; injuries that we are all accountable to help heal.

As co-editors, we are personally accountable for change and we are taking actionable steps against racism, genderism, sexism, agism, classism, ableism, etc., that influence systemically oppressed communities. We are advocating for

Angela L. Lamson

lamsona@ecu.edu

1 Human Development and Family Science, East Carolina University, 112 Redditt House, Mailstop \#505, Greenville, NC 27858-4353, USA

2 Department of Family Social Science, University of Minnesota, Twin Cities Campus, Saint Paul, MN, USA a more equitable future for our field and our nation. In addition to putting forward anti-oppression statements in our universities, we hold ourselves accountable and are using our academic and professional platforms to encourage actionable steps toward change.

There are three changes that we advance in this special issue: First, we mark this issue with what we are naming horizontal editorship and authorship. For too long, a hierarchical model has been used to rank the names of each author or editor even when-or especially when-duties were evenly distributed across contributors. Too often, editors and authors of color, gender and sexual minorities, or those with diverse abilities are not recognized. Their work is left uncited and unacknowledged by oppressive institutional policies that narrow our understanding about what it means to have a reputable manuscript (e.g., recognizing only top tier or high impact outlets; Mason \& Merga, 2021).

Second, we wanted to include a series of articles that highlight issues experienced in systemically oppressed communities, and stress the role of MedFTs as providers, leaders, educators, scholars, and ambassadors for change. Authors reflective of a wide variety of social locations and areas of work were invited to contribute to this special issue. Moreover, a call for submissions was widely distributed to encourage MedFTs not yet known to the editorial team to submit their work. We wanted to design a special issue that was as inclusive as possible.

Third, this special issue offers a variety of articles that speak to our accountability for actionable change. Each one is grounded in CJ Peek's Three-World View (2008), which is a lens that offers a way to stay attuned to the clinical, operational, financial, and educational factors that influence each of us and often perpetuate or protect from further harm on our biological/physical, psychological/behavioral/emotional, social/relational, and spiritual/meaning-making selves and communities. Note that the use of "Four-World-View" in this special issue is a title adaptation to Peek's "Three-World View." Peek refers to the fourth world as "hidden" in his lens 
because not all systems have a formalized training/education component. However, in this special issue the editors opted to feature it as critical component to systems-level changethereby elevating it to a "Four-World-View."

Rather than asking each author to operationalize the FourWorld View in each article, we provide a description that captures a way to consider the four worlds in context of the many roles held by MedFTs and other healthcare professionals as we interface with the intersection of systemically oppressed communities. The clinical world represents the patient- or population- encounters that are intended to focus on quality care and interactions grounded in healing, science, and ethics. The operational world implies that many operating systems are at work to facilitate efficiency. This world attends to process improvement, workflow, and policies and procedures that govern the health care system's operations. The financial world, while attending to healthcare systems' fiscal sustainability, also seeks to monitor price and maximize value. Foundational to this world are return-on-investment, ethical business practices, cost offset, and the best use of resources. The education world has historically been affiliated with medical training sites, but the utility of education extends well beyond these settings. Healthcare systems need continuous training mechanisms essential to the onboarding of new team members and retraining of existing ones. A strong educational world helps improve model fidelity.

Ironically, when Peek (2008) described these worlds, he shared that this term was used because in most disciplines we are trained to function in one domain (e.g., trained as a clinician, but not as a policymaker), yet those who are served by health care - or not—are continuously influenced by the four worlds when attempting to get their needs met. For example, the clinical world is supposed to represent quality; the operational world, efficiency; the financial world, value; and the educational world, informed decision making. Yet, oftentimes systemically oppressed communities are not invited to the conversation. Consequently, their voices and requests go unheard, and their actions and bodies, ignored.

When describing the creation of the Four-World view, Peek (2008) shared that the conceptualization emerged as a way to reconcile and harmonize the worlds among persons with different native languages. He shared the work of Peter Ossorio (1985) and distinctive psychology, who described native language as the communication associated with one's discipline (e.g., how clinicians speak in contrast to the ways that chiefs of operations or billing specialists speak). We push this point further to advocate for the four worlds to literally be considered in context of a native language. That is: How are MedFTs engaging in cultural awareness, sensitivity, and humility? How do we recognize the depths of disparities in our patients, students, research participants, and the communities in which we live and work? What native languages are overlooked, silenced, or ignored? Those who seek out our support deserve inclusive health environments, quality care, equity in policies that govern their interactions, access to resources, and their voice as part of the mutual and reciprocal education needed to alter our systems and communities.

Below we provide a snapshot of the seven manuscripts selected for the special issue on Medical Family Therapy for Contemporary Family Therapy. We hope that these articles compel each reader to take them to their professional and personal spaces, and use them as a way to engage in conversations with others who are motivated by the material such that new ways to eradicate systemic oppression in our communities, care practices, and beyond are advanced.

(1) Dr. Kelly Roberts and Ms. Andrea Trejo boldly put into this special issue an unveiling of layers of institutional racism that exist within healthcare practice, policy, billing systems, and educational accrediting systems. A call to action is conveyed by the authors toward MedFTs to "heal thy self, healthcare system, and local, state, federal, tribal, and other government systems."

(2) Drs. Chalandra Bryant, Leslie Anderson, and Maxine Notice deconstruct the concept of resilience by highlighting contextual factors that influence peoples' ability to adapt under dire circumstances. A model is extended to readers as a guiding framework for understanding connections between resilience (as a process and outcome), physiological disturbances, and psychological disruptions. Also addressed is the need for culturally responsive medical family therapists to intervene in the lives of individuals whose health has been compromised by repeated exposure to stress and sheer determination to demonstrate resilience.

(3) Drs. Angela Lamson, Jennifer Hodgson, Francisco Limon, and Ms. Cheng Feng present a longitudinal service delivery model for integrated care in racially, ethnically, and economically underserved communities. Their work highlights the importance of decisionmaking metrics for systems that predominately engage with underserved and systemically oppressed patients and families. They offer recommendations about ways that MedFTs can facilitate provider and administrative buy-in, assess model fidelity, and strive for quality outcomes.

(4) Dr. Tai Mendenhall, Ms. Doneila McIntosh, and Mr. David Hottinger attend to spiritual healing and elements of spirituality in MedFT, as well as the chasm in care when spirituality is not considered across the four worlds. They help enlighten readers to think about ways they can bring spirituality into their work, as it is currently an underutilized and poorly attended to area of health. 
(5) Dr. Vaida Kazlauskaite offers a compelling clinical manuscript about how to talk with young children and adolescents following the death or chronic health diagnosis of a parent or guardian. Readers are provided with numerous examples of effective communication models when delivering difficult health news with families.

(6) Drs. Melissa Welch, Jennifer Hodgson, Katharine Didericksen, Angela Lamson, and Thompson Forbes present the importance family involvement in the treatment of adults' cognitive decline and dementia. Their comprehensive review indicates that family-centered care and family engagement contribute to improved health outcomes, better care, and improved caregiver satisfaction. Their review also underscores the inconsistent application of family-centered practices.

(7) Ms. Corin Davis and Drs. Angela Lamson and Kristin Black focus on the importance of recruitment and retention of a diverse physician population across all stages of education and subsequent career lifespan, from pre-medical school to post-training practice. The authors specifically attend to marginalization in the recruitment and retention processes of historically (and systemically) oppressed medical students, residents, and practicing physicians.

Whether you are a researcher, educator, clinician, supervisor, policy writer, or administrator, this special issue speaks to our accountability for contributing to the creation of a more equitable healthcare system. Researchers and clinicians must develop, implement, and evaluate interventions indicated for diverse populations to move the field of MedFT forward. Policy advocates must examine previous policies and laws and put forward a call for changes that promote equity in access, treatment, and organizational systems. Educators are charged with delivering the knowledge and skills needed to ensure that healthcare professionals are up-to-date and practicing with integrity, while also recognizing the history of health care delivery and education and how that history may influence modern-day biases. Supervisors' accountability promotes fidelity to inclusive, equitable, and ethical workspaces. Administrators' oversight includes advocacy for quality health care, efficient workflow, billable and reimbursable services, and supportive professional training environment.

MedFTs are uniquely poised to lead in these advancements. We understand relational thinking, ethics, and practices. We are effective conveners and see the ripple effects of change as we touch all parts of an integrated and complex system. This special issue will persuade readers toward selfexamination. It will highlight the rarely discussed reasons that health outcomes in this country are not progressing despite ever-advancing medicines and technologies. Until we are open to being uncomfortable, we cannot create space for the changes that are needed.

\section{References}

Engel, G. L. (1977). The need for a new medical model: A challenge for biomedicine. Science, 196, 129-136. https://doi.org/10.1126/ science. 847460

Engel, G. L. (1980). The clinical application of the biopsychosocial model. American Journal of Psychiatry, 137, 535-544. https:// doi.org/10.1176/ajp.137.5.535

Mason, S., \& Merga, M. (2021, October 11). Less 'prestigious' journals can contain more diverse research, by citing them we can shape a more just politics of citation. London School of Economics and Political Science (LSE) Impact Blog. https://blogs.lse. ac.uk/impactofsocialsciences/2021/10/11/less-prestigious-journ als-can-contain-more-diverse-research-by-citing-them-we-canshape-a-more-just-politics-of-citation/?fbclid=IwAR1p0A6Y NQWEK4_J4TkVnctxeA8x1pWLYQv9iVAJ36Kac3CH3NtE5Nl $7 \mathrm{n} 3 \mathrm{I}$

Ossorio, P. (1985). An overview of descriptive psychology. In K. Gergen \& K. Davis (Eds.), The social construction of the person (pp. 19-40). Springer.

Peek, C. J. (2008). Planning care in the clinical, operational, and financial worlds. In R. Kessler \& D. Stafford (Eds.), Collaborative medicine case studies: Evidence in practice (pp. 25-38). Springer.

Wright, L. M., Watson, W. L., \& Bell, J. M. (1996). Beliefs: The heart of healing in families and illness. Basic Books.

Publisher's Note Springer Nature remains neutral with regard to jurisdictional claims in published maps and institutional affiliations. 